\title{
Decision-Making and Negotiation in Innovation \& Research in Information Science
}

\author{
Maria José Sousa ${ }^{1}$ D . Álvaro Rocha ${ }^{2}$
}

Accepted: 3 October 2020 / Published online: 16 October 2020

(C) Springer Nature B.V. 2020

\begin{abstract}
This Special Issue is dedicated to current issues in Decision-making and Negotiation in Innovation \& Research in Information Science. Despite all the research around Decision-making and Negotiation the main theoretical and practical importance of this issue is the focus on studies oriented to innovation \& research (I\&R) in information science. The purpose is to analyse the decision-making processes for practical problem-solving and to understand the ways information systems can be a trigger in the process. To achieve this objective several articles will present models, tools and frameworks to help improving the decision-making and negotiation processes, and the research findings support the conclusion that information systems can help to achieve better decisions and facilitate the negotiation processes.
\end{abstract}

Keyword Decision-making $\cdot$ Negotiation $\cdot$ Innovation $\cdot$ Research $\cdot$ Information science

\section{Introduction}

Decision-making processes have been studied by several authors (Dhami et al. 2015; Curseu \& Schruijer 2012), and it can be considered as a mental process in which human beings make a choice among several alternatives. However, with the increasing complexity of real decision-making problems, decision makers frequently face the challenge of characterizing their preferences in an uncertain context. Decentralised decision-making and real-time response to the unforeseen changes are two important factors that affect the flexibility, required for a production chain to follow demand. The main methodologies that can improve decision-making processes are decision trees, which are traversed and evaluated via user-defined objective

Maria José Sousa

maria.jose.sousa@iscte-iul.pt

1 Instituto Universitário de Lisboa, Business Research Unit, Lisboa, Portugal

2 ISEG, Universidade de Lisboa, Lisboa, Portugal 
functions. The real-time information, required for monitoring the system status and for generating valid alternatives, is obtained through integration with information systems (Church et al. 2016; Sabherwal and King 1995).

In this context, the strategic potential of information systems is well recognized for practitioners and academics for supporting decision-making processes-Define the problem; Identify conditioning factors; Develop potential alternatives; Analyse the alternatives; Select the best alternative; Implement the decision; Establish a control and evaluation system. Decision Support Systems (Church et al. 2016; Huber 1981) are designed to use rational models for better decision-making processes (Song et al. 2017). A key issue is the access to current, comprehensive, and reliable information for informed decision-making in integrated management processes (Cappel and Windsor 2000). Both technological and institutional responses are important to understanding users' needs for decision support drivers.

The articles in this special issue contribute to the development of this scientific discussion and analyse the ways information systems contribute for facilitating and improving the operational decision-making processes (Fischer et al. 2015; Fox \& Poldrack 2014; Frederick 2005). This editorial presents an overview of the background of decision-making and negotiation in Innovation and Research in Information Science, and a brief theoretical perspective.

The review of the literature will focus on decision-making and negotiation in innovation and research in information systems, followed by a discussion on the development of the research in decision-making and negotiation in I\&R in information science, and a description of decision-making and negotiation in I\&R in information science research trends. We end with a summary of the papers in this special issue.

\section{Review of Decision-making and Negotiation in I\&R in Information Science}

Decision-making is represented by bounded rationality; there is a strong and vital connection between the essence and weaknesses of human decision-making and organizational innovation and information systems as a support. Cyert and March (1963) found that the reach of decision-making in an existing organization is restricted by prior decisions (Greiff et al. 2015), either directly or implicitly, as well as by moral obligations of individuals, and by access to relevant information.

Moreover, decisions are strategic for the actions taken, the resources allocated, or the precedents defined (Mintzberg et al. 1976), as the decisions taken by the managers and employees can influence organizational performance. Selznick (1957) differentiates (critical) strategic decisions from the routine ones, but both are important for the definition of the strategy and the operations of an organization. Drucker (2002) stresses that decisions can be strategic and multidimensional and will affect the company's future. Top managers' fundamental position is seen as defining organizational goals and strategy, with policies interfering to establish the relationships between organizations and their resource environments. Strategy and strategic decisions thus serve as a major predictor of the success of innovative companies- that 
is why information systems become, over the years, more and more important to access, organize and produce relevant information, transformed in indicators, and metrics, in order to support the decisions in business analytics strategies (Rathwell and Burns 1985).

Operational decisions, unlike strategic decisions, are internally based and take more of the time and resources of the organization, as they are the decisions taken regarding the everyday operation of the organization, but also to the introduction of innovation processes-mainly incremental innovations, that need to be negotiated between employees and managers-explicating the pros and cons of those innovations. Examples of those kinds of decisions would be resource distribution, scheduling tasks, and performance management (Burton Leitch and Tuttle 2001).

Ackoff (1970) describes planning as taking anticipatory decisions, consisting of two strategy elements: strategic and tactical. Strategic planning decisions are wideranging decisions, have long-term implications and are connected to organizational objectives, therefore they are negotiated within the organization. Tactical decisions are about choosing the most effective means of achieving the objectives set out in the strategic plan. Ackoff emphasizes that both are required to optimize the success of the company and that corporate-level preparation is more strategic than an an other hierarchical stage.

The key argument is that the essence and success of the company is directly influenced by such decisions, and consequently by the type of information systems that support those decisions (Church et al. 2016). Braybrooke and Lindblom (1963) emphasize the difficulty of organizational decision-making processes and clarify that the integration of parts of the knowledge is a rather complicated process and thus constrained by the ability to understand the relationship between all parts. Therefore, it is not a techno-scientific feat but a product of realistic procedures. The approach to decision-making process assumes nevertheless several limitations: The decision-making process is based on the information available; there is little ability for problem-solving and difficulty to access to a database of solutions; information inadequacy; and information systems costs. In addition, Braybrooke and Lindblom (1963), point out the method of measuring the outcomes of the decision-making and negotiation process (Bellucci and Zeleznikow 2005), the combination of the evidence and the effects observed.

New information systems based on Artificial Intelligence and Big Data technologies introduce new challenges associated with decision-making (Duan et al. 2019), offering infinite possibilities of interaction and integration to support or replace human decision-makers. One of the main problems is interoperability of information systems, that can be in part solved by distributive models-driven platforms for parallel coordination of multiple negotiations in data-intensive collaborative working environments. Moreover, previous research shows that although collaboration technology can improve the exchange of information during team decision-making (McNamara et al. 2008), one of the challenges is that better discussion often does not lead to better decisions, and the study of the impact of individual information processing on team decision-making, is still in a preliminary phase.

For decision-making processes and negotiation in organisations evolutionary game theory may also help to know the right decision to make in specific situations. 
For instance, in strategic innovation in terms of evolutionary game theory scenarios (Baniak and Dubina 2012) covering different decision methods can lead to increase the innovations success in the markets and performance optimization. Applying game theory principles to organizations can promote cooperation between different enterprises and can effectively reduce cost, and production and market risks.

To analyse the research trends on decision-making, and negotiation in innovation and research in information science, a bibliometric analysis was performed using the main search keywords Decision-making + Negotiation + Information Systems, using the scientific search engine b-On, which aggregates and accesses all the major scientific databases.

The analysis was made from 1900 till the beginning of September of 2020, and then reduced for the last five years (Table 1), as information science has had an enormous evolution in terms of decision-making and negotiation information systems.

After applying the criteria defined in Table 1, the final number of papers for analysis is $155(n=155)$ for the current research.

The analysis of the results of the bibliometric search was made using the scientific software VOSviewer for the visualization of the networks regarding the keywords and the co-authoring of the articles considered for this analysis $(n=155)$.

This analysis was guided by the two following research questions: RQ1: What were the main research keywords in studies of decision-making and negotiation in innovation and research in the field of information science?; and RQ2: Who were the main authors in studies of decision-making and negotiation in innovation and research in the field of information science?

To answer research question 1, a network of all keywords is represented in the Fig. 1. It shows that the main research keywords of the articles analyzed are decision-making, group decision-making, group decisions and negotiation, negotiation, multi-agent systems, information, and ontology.

Regarding the keywords linked, it is possible to visualize the network, and identify the keywords that appear together/linked in each article. This will help to visualize and to know the topics covered by the research in the field and to identify research trends (Fig. 2).

To answer research question 2, a representation of the network of co-authorships is presented in Fig. 3, since 2015 to 2019, being a profusion of co-authorships

Table 1 Number of Articles Found according to criteria of exclusion

Keywords: Decision-making + Negotiation + Information systems

543,771 Scientific papers in journals since 1900

Last five (2015-2020): 194,380

Exclusion criteria: Equivalent terms and search in the whole text: 366

Integral text: 307

In English: 269

Duplicates removed: 173

Peer reviewed: 155 


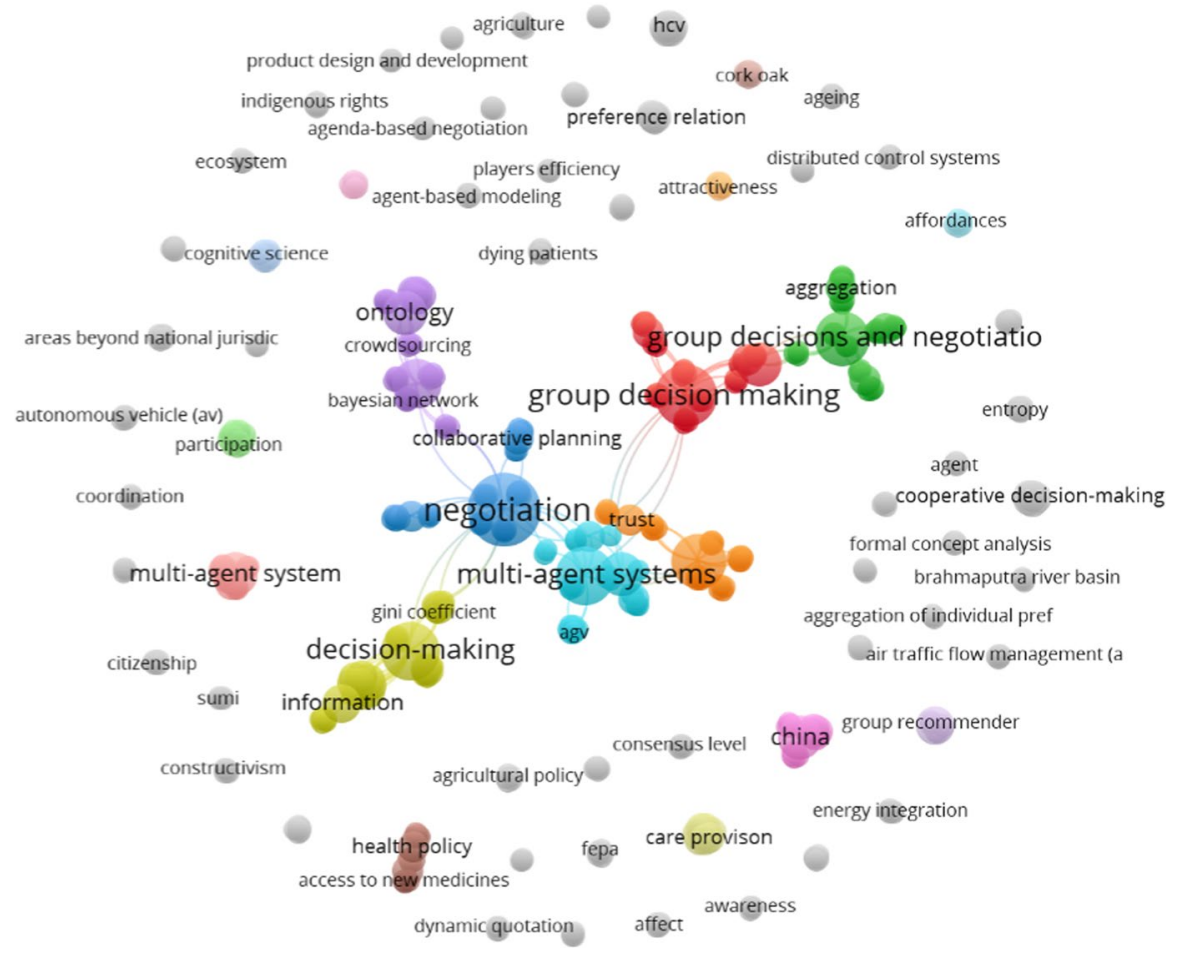

Fig. 1 Network of All Keywords

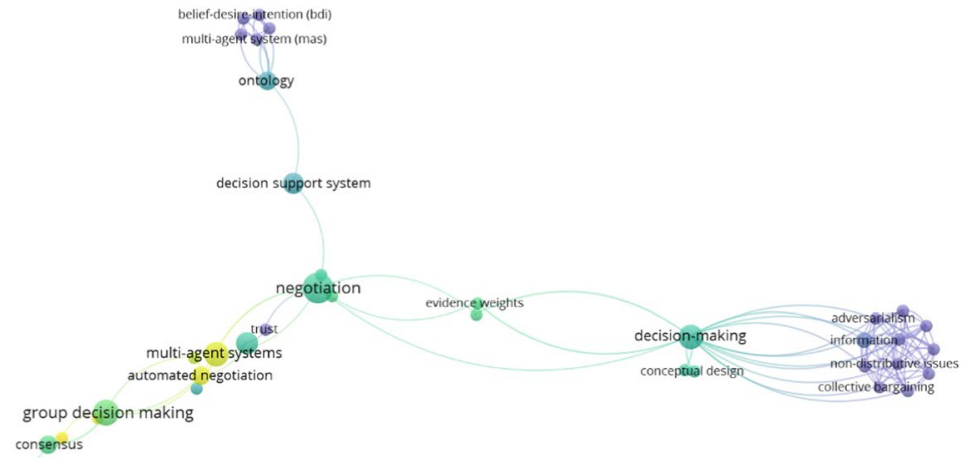

group decisions and negotiatio

As vosviewer

Fig. 2 Network of Linked Keywords 
\& Vosviewer

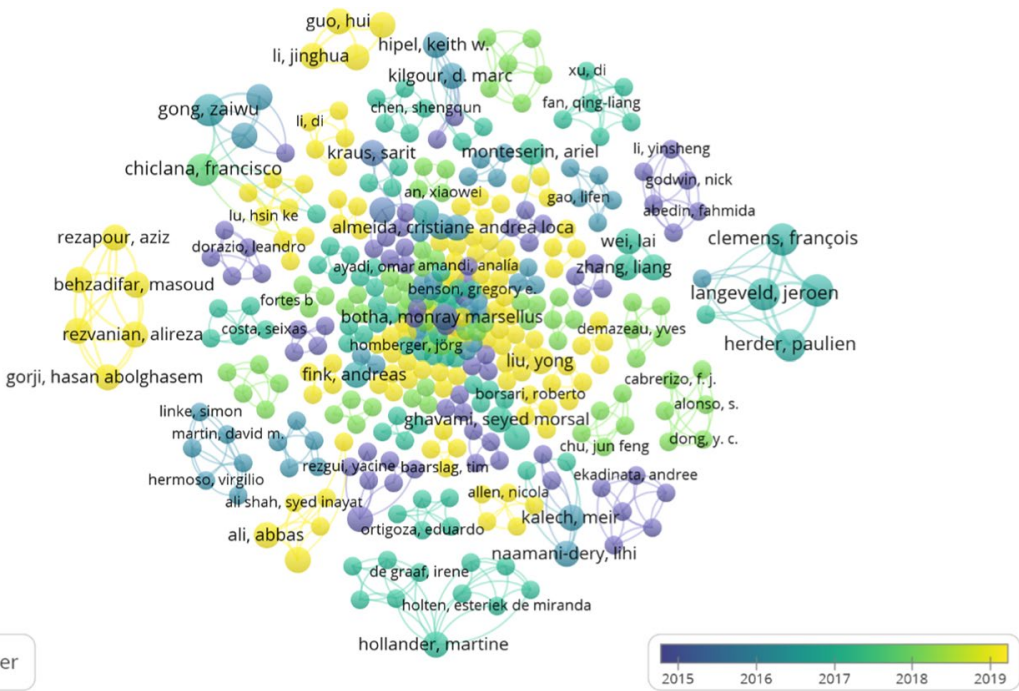

Fig. 3 Co-Authorships

represented by the yellow colour, which means an effort of collaboration of the authors researching in this field.

\section{Overview Special Issue}

This special issue of Group Decision and Negotiation Journal features five new studies, which forge a strong connection to theory and promote the transfer of research results to real-world management practices. They are contributions to enhance knowledge in Group Decision and Negotiation (GDN) processes in Innovation and Research in Information Science. Decision-making and Negotiation are management tools for distinct approaches to Innovation and Research agenda in order to facilitate a response to the changes occurring in a turbulent environment, a means of improving the processes of Innovation and Research in a macro and a micro level. The papers in this issue contribute to theory development and empirical studies conceptualizing the decision-making and negotiation constructs, in various types of studies as traditional, self-initiated, reviews of finished projects, theoretical, or model-building contributions.

In summary, these articles focus on technological innovations supporting decision-making and negotiations that forge a strong connection to these or other bodies of theory, with an emphasis on novelty and usefulness with the objective of joining together scholars who are working at the forefront of this research domain. This includes strong theoretical, conceptual and empirical papers using quantitative or qualitative approaches to Decision-Making and Negotiation field.

A summary of the research presented in each article of this special issue is provided below: 
The article "Bargaining game with altruistic and spiteful preferences" by Zhongwei Feng et al. researches the players preferences and attitudes when facing real-life problems. In their research the authors model the players preferences, reconsidering the principles of the Rubinstein bargaining game. They construct a subgame based on the principle of perfect equilibrium (SPE), where a player's strategy depends on the opponent's share through altruistic and spiteful preferences. Then, they perform a comparative statistics analysis with respect to players' altruism and spite. The research shows that the equilibrium share of a player is negatively related to the opponent's global spite and his own global altruism, and positively to global altruism of the other one and the global spite of himself. It is also found that the impact of the intrinsically altruistic and spiteful levels of a player on equilibrium share depends on this player's attitudes towards the opponent. Furthermore, it is found that a more positive attitude towards the opponent leads to the increase (decrease) of this player's share if this player is more (less) intrinsically altruistic than the opponent. Finally, they establish a relationship with the asymmetric two-person Nash bargaining game. It is found that the bargaining power of a player decreases with the globally altruistic and spiteful preferences of himself and increases with the opponent's. It is further found that the effects of players' attitudes towards the opponent on their own bargaining power depend on the gap between the intrinsic altruistic and spiteful levels of players.

The article "Developing a Multi-Methodology for Conflict Resolution: Case of Yemen's Humanitarian Crisis" by Ellakkis, et al. studies conflict analysis, focusing on the development and application of a multi-methodological intervention benefiting from the advantages of Soft OR and Game theory. Accordingly, the paper contributes to the journey making methodology through developing new concepts, making it richer information-wise, and thus more reliable. Moreover, it applied the proposed model for the Saudi-led war on Yemen, where the latter faces one of the world's worst humanitarian crises. In addition, a stability analysis considered investigating stable scenarios (equilibrium) for all parties. Ultimately, their findings indicate that only one stable scenario can stop the war and resolve one of the world's worst humanitarian crises.

The article "Game Adaptation by using Reinforcement Learning over Meta Games" by Reis, et al. proposes a Dynamic Difficulty Adjustment methodology to achieve automatic video game balance. The balance task is modelled as a meta game, where actions change the rules of another base game. Based on the model of Reinforcement Learning (RL), an agent assumes the role of a game master and learns its optimal policy by playing the meta game. The innovation of the research is a new methodology that extends traditional RL by adding the existence of a meta environment whose state transition depends on the evolution of a base environment. The authors propose a Multi Agent System training model for the game master agent, where it plays against multiple agent opponents, each with a distinct behavior and proficiency level while playing the base game. They conduct an experiment on an adaptive grid-world environment in single player and multiplayer scenarios. The results are expressed in two ways: the resulting decision-making by the game master through gameplay, which must comply in accordance to an established balance objective by the game designer; the initial conception of a framework for automatic 
game balance, where the balance task design is reduced to the modulation of a reward function (balance reward), an action space (balance strategies), and the definition of a balance space state.

The article "Dynamic expert reliability-based feedback mechanism in consensus reaching process with distributed preference relations" by Xue et al. discusses a group consensus reaching process (CRP) based on dynamic expert reliability. The researchers use a method designed to support uncertain multi-attribute group decision-making in situations where experts in a group use distributed preference relations (DPRs) to express their preferences when deciding. In the method, it is assumed that a predefined consensus requirement can be specified and must be satisfied before consensus-based solutions are generated. If the requirement is not satisfied, expert reliability is first defined and calculated in terms of data depicted by the experts, and then used to design an expert reliability-based feedback mechanism composed of identification and suggestion rules to help identify the DPRs hindering CRP. Additionally, experts update their DPRs to accelerate convergence to CRP. The problem of selecting an appropriate supplier in a high-end equipment manufacturing enterprise located in Changzhou, Jiangsu Province, China is analyzed by the proposed method to demonstrate its applicability and validity.

Finally, the article "Supply chain innovation research: a conceptual approach of information management with game theory" by Zambujal-Oliveira investigates the problem of information sharing throughout the supply chain, based on the amount of demand information that supply chain participants need to share in order to create the appropriate capacity to supply it. The researcher analyses if the player (producer) has the incentive to inflate his demand, waiting for the other player (supplier) to believe in it and to create additional capacity. The research tries to analyse how the player (producer) can increase the credibility of their forecast in order to convince the supplier to invest in this additional capacity. The evaluation of game theory as a suited methodology to demonstrate and quantify the value of information sharing throughout the supply chain is the methodology proposed in this research.

Acknowledgements The Guest Editors would like to express their deep gratitude to the Editor in Chief Gregory Kersten for his support during several months of work together and to express their deepest sorrow for his passing during the special issue development. We also want to thank to the Ad-Interim Co-Editors-in-Chief: Gert-Jan de Vreede and Mareike Schoop, and the authors for writing such excellent papers. Another thanks to the many anonymous referees for carefully reviewing the manuscripts and for providing many helpful suggestions for improving them. Additionally, the Guest Editors would like to state their appreciation to the many people who assisted in making this Special Issue a success. Finally, the Guest Editors would like to thank to AISTI for organizing the WorldCist19 conference and this Special Issue.

\section{References}

Ackoff RL (1970) A concept of corporate planning. Wiley, New York

Baniak A, Dubina I (2012) Innovation analysis and game theory: a review. Innovat Manage Policy Pract 14(2):178-191

Bellucci, E., \& Zeleznikow, J. (2005). Trade-off manipulations in the development of negotiation decision support systems. In: Proceedings of the Annual Hawaii International Conference on System Sciences, 36. 
Braybrooke D, Lindblom CE (1963) A strategy of decision. Free Press, New York

Burton FG, Leitch RA, Tuttle BM (2001) A user's willingness to adopt a new information system: the influence of the decision-making improvements and performance-monitoring dimensions of the system. J Inf Syst 15(2):61-79

Cappel JJ, Windsor JC (2000) Ethical decision-making: a comparison of computer-supported and face-toface group. J Bus Ethics 28(2):95-107

Church KS, Schmidt PJ, Smedley G (2016) Casey's collections: a strategic decision-making case using the systems development lifecycle-planning and analysis phases. J Emerg Technol Account 13(2):231-245

Curseu P, Schruijer S (2012) Decision styles and rationality: an analysis of the predictive validity of the general decision-making style inventory. Educ Psychol Meas 72(6):1053-1062

Cyert RM, March JG (1963) A Behavior theory of the firm. Prentice Hall, Englewood Cliffs

Dhami MK, Mandel DR, Mellers BA, Tetlock PE (2015) Improving intelligence analysis with decision science. Perspect Psychol Sci 10:753-757

Drucker P (2002) Managing in the next society. Truman Talley, New York

Duan Y, Edwards JS, Dwivedi YK (2019) Artificial intelligence for decision-making in the era of Big Data—evolution, challenges and research agenda. Int J Inf Manage 48:63-71

Fischer A, Holt DV, Funke J (2015) Promoting the growing field of dynamic decision-making. J Dyn Decis Mak 1:1-3

Fox CR, Poldrack RA (2014) Prospect Theory and the brain. Handbook of Neuroeconomics. Elsevier, New York

Frederick S (2005) Cognitive reflection and decision-making. J Econ Perspect 19(4):25-42

Greiff S, Fischer A, Stadler M, Wüstenberg S (2015) Assessing complex problem-solving skills with multiple complex systems. Think Reason 21:356-382

Huber GP (1981) The nature of organizational decision-making and the design of decision support systems. MIS Q Manage Inf Syst 5(2):1-10

McNamara K, Dennis AR, Carte TA (2008) It's the thought that counts: the mediating effects of information processing in virtual team decision-making. Inf Syst Manage 25(1):20-32

Mintzberg H et al (1976) The structure of "unstructured" decision process. Adm Sci Q 21(2):246-275

Rathwell MA, Burns A (1985) Information systems support for group planning and decision-making activities. MIS Q Manage Inf Syst 9(3):255-271

Sabherwal R, King WR (1995) An Empirical taxonomy of the decision-making processes concerning strategic applications of information systems. J Manag Inf Syst 11(4):177-214

Selznick P (1957) Leadership in Administration. Harper and Row, New York

Song Q, Chan SH, Wright AM (2017) The efficacy of a decision support system in enhancing risk assessment performance. Dec Sci 48(2):307-335

Publisher's Note Springer Nature remains neutral with regard to jurisdictional claims in published maps and institutional affiliations. 